\title{
Androgen receptor mRNA expression is a predictor for recurrence-free survival in non-muscle invasive bladder cancer
}

\author{
Masato Yasui ${ }^{1 \dagger}$, Takashi Kawahara' ${ }^{1}$ Koji Izumi ${ }^{1}$, Masahiro Yao ${ }^{2}$, Yukari Ishiguro' ${ }^{1}$ Hitoshi Ishiguro ${ }^{2,3}$, \\ Hiroji Uemura ${ }^{1}$ and Yasuhide Miyoshi ${ }^{1 *}$ (D)
}

\begin{abstract}
Background: Non-muscular invasive bladder cancer (NMIBC) has a high risk of recurrence. As androgen receptor $(A R)$ reportedly affects bladder cancer, we assessed the correlation between NMIBC recurrence and tumor $A R$ expression in Japanese patients.

Methods: We retrospectively reviewed 53 specimens of non-metastatic NMIBC, with recurrence-free survival (RFS) as the primary endpoint. We used real-time quantitative polymerase chain reaction to quantify AR mRNA expression. Kaplan-Meier product-limit estimators were used to assess RFS distribution, log-rank tests to analyze differences in RFS between high- and low-risk groups; and multivariate analyses of AR mRNA expression and other clinicopathological factors to predict independent factors for RFS.

Results: The high AR mRNA-expressing group $(n=43)$ tended to have a longer median RFS (not reached) than did the low-AR group ( $n=10 ; 9.04$ months; $P=0.112$ ). Multivariate analysis showed female sex (hazard ratio [HR]: 7.360, 95\% Cl: 1.649-32.856, $P=0.009$ ), tumor size $\geq 3 \mathrm{~cm}$ (HR: 23.697, 95\% Cl: 4.383-128.117, $P<0.001$ ) and low AR mRNA expression (HR: $0.202,95 \% \mathrm{Cl}: 0.048-0.841, P=0.028$ ) to be independent predictors of shorter RFS.

Conclusion: Our study showed that low AR mRNA expression level is an independent risk factor for RFS in Japanese patients with NMIBC. Further studies are necessary but $A R$ expression might be a new indicator of recurrence of NMIBC.
\end{abstract}

Keywords: Bladder cancer, Non-muscular invasive, Androgen receptor, RT-qPCR, Recurrence

\section{Background}

Bladder cancer (BC) is a common malignancy, with an estimated 429,800 new cases and 165,100 deaths in 2012, worldwide [1]. Urothelial carcinoma is the most common type of $\mathrm{BC}$, and it is stratified to non-muscular invasive bladder cancer (NMIBC) and muscular invasive bladder cancer (MIBC). Patients with MIBC have a high risk of disease progression and metastasis and usually need aggressive treatments, such as radical cystectomy or chemotherapy; whereas NMIBC has a better prognosis and can be treated curatively by transurethral

\footnotetext{
* Correspondence: miyoyasu@med.yokohamac-cu.ac.jp

${ }^{\dagger}$ Masato Yasui and Yasuhide Miyoshi contributed equally to this work.

'Department of Urology and Renal Transplantation, Yokohama City

University Medical Center, 4-57 Urafune-cho, Minami-ku, Yokohama 232-0024,

Japan

Full list of author information is available at the end of the article
}

resection of bladder tumor (TUR-BT). However, NMIBC has a high risk of recurrence and can progress to MIBC. To prevent recurrence and progression, intravesical instillation (IVI) of anthracycline or bacillus Calmette-Guérin (BCG) has been administered, but about $50 \%$ still recur. As the treatment has not changed for decades, new studies leading to new treatments are needed to prevent recurrence and progression.

Men tend to be diagnosed about four times more often than women [2], which implies that BC is an endocrine-related cancer. Androgen receptor (AR) signaling has been suggested to have an important role in $\mathrm{BC}$ occurrence and progression by previous studies [3-18].

Thus, in this study, we assessed the correlation between NMIBC recurrence and tumor AR expression in Japanese patients, by quantifying $A R$ mRNA expression

(c) The Author(s). 2019 Open Access This article is distributed under the terms of the Creative Commons Attribution 4.0 International License (http://creativecommons.org/licenses/by/4.0/), which permits unrestricted use, distribution, and reproduction in any medium, provided you give appropriate credit to the original author(s) and the source, provide a link to the Creative Commons license, and indicate if changes were made. The Creative Commons Public Domain Dedication waiver (http://creativecommons.org/publicdomain/zero/1.0/) applies to the data made available in this article, unless otherwise stated. 
with real-time quantitative polymerase chain reaction (RT-qPCR).

\section{Methods \\ Patients}

We retrospectively reviewed 53 specimens of TUR-BT among 51 patients with non-metastatic NMIBC treated at Yokohama City University Medical Center and Yokohama City University Graduate School of Medicine from 2008 to 2015. In the two patients, specimens were obtained two times at the time of initial TUR-BT and at the time of recurrence. Samples for RT-qPCR came from biopsies performed during TUR-BT procedures. Both primary and recurrent NMIBC was diagnosed by TURBT. The experimental procedures were conducted in accordance with the ethical standards of the Helsinki Declaration. This study was approved by the institutional review board of Yokohama City University Medical Center. Informed consent to participate in the study were obtained from all subjects.

\section{Clinical assessments}

The primary endpoint of this study was recurrence-free survival (RFS), which was defined as the time between the date of the initial TUR-BT and the date when the TUR for the recurrent BC was performed. Cancers detected in second-look TUR were not defined as recurrence, and RFS was counted from the first TUR-BT. Histopathological factors were assessed by pathologists specialized in uropathology.

\section{Real-time PCR}

$A R$ mRNA level was assessed by quantitative RT-qPCR method. We obtained $53 \mathrm{BC}$ tissue specimens by TUR-BT to analyze gene expression. Total RNA $(0.5 \mu \mathrm{g})$, which was isolated from the bladder tissue specimens, using Isogen (NipponGene, Tokyo, Japan), was reverse transcribed using $1 \mu \mathrm{M}$ oligo (dT) primers (Qiagen, Germantown, MD, USA) and 4 units of Omniscript reverse transcriptase (Qiagen) in a total volume of $20 \mu \mathrm{L}$. Gene expression for $A R$ and human glyceraldehyde-3-phosphate dehydrogenase (GAPDH) were examined by real-time qPCR, using $A R$ primers (Applied Biosystems, Foster City, CA, USA). Gene expressions were determined using TaqMan ${ }^{\circ}$ Gene Expression Assays (Applied Biosystems, Grand Island, NY, USA). All data were normalized to GAPDH; expression of one tumor was assumed to be 1 and used as reference. The $2^{-\Delta \Delta C T}$ method was used to calculate relative amounts of target genes.

\section{Statistical analysis}

The cut-off point for the $A R$ mRNA level was determined by a web-based calculator cut-off finder (http://molpath. charite.de/cutoff.) and median values were used as the cut-off points for other factors to categorize continuous measurements [19]. Spearman's rank-order correlation was used to measure the association between $A R$ mRNA expression level and clinical factors. A Kaplan-Meier product-limit estimator was used to assess RFS distribution. Log-rank tests were used to analyze differences in RFS between the high- and low-risk groups. Univariate and multivariate COX models were used to analyze factors for predicting RFS. We derived relative risks and 95\% confidence intervals (95\% CIs). All tests were two-sided; alpha $=0.05$ was considered significant. All analyses were conducted using IBM SPSS Statistics software for Windows, version 22 (IBM Corp., Armonk, NY, USA).

\section{Results}

Patients' characteristics are shown in Table 1. Patients' median age at TUR-BT was 74.1 years (range: $40.8-88.8$ years) and $48(90.6 \%)$ patients were male. Of the 53 patients, $11(20.8 \%)$ were recurrent $\mathrm{BC}$ and 9 patients (17.0\%) were recurred within 1 year. Tumor grade was low in 39 patients (73.6\%) and high in 14 patients (26.4\%). Pathological T-stage was pTa in 42 patients (79.2\%) and pT1 in 11 patients (20.8\%). Tumors were single in 24 patients $(45.3 \%)$ and multiple in 29 patients (54.7\%). Tumor size was $\geq 3 \mathrm{~cm}$ in 7 patients (13.2\%); concurrent carcinoma in situ (CIS) was found in $2 \mathrm{pa}$ tients $(3.8 \%)$. Immediate IVI using anthracycline was administered in 51 patients (96.2\%) and additional adjuvant IVI using either BCG or anthracycline was administered in 12 patients (22.6\%). Six patients (11.5\%) underwent second TURs.

We found no significant association between $A R$ mRNA expression level and other clinicopathological factors (Spearman's rank-order correlation; Table 2).

The Kaplan-Meier curve for RFS is shown in Fig. 1. Within a median observation period of 10.2 (range: 0.429.5) months, recurrence occurred in 17 patients (32.1\%).

We stratified the 53 patients into two groups: 43 in the high $A R$ mRNA-expressing group and 10 in the low $A R$ group. The high $A R$ group showed a tendency for longer median RFS (not reached) than did the low- $A R$ group (9.04 months, $P=0.112$; Fig. 2).

Results of univariate and multivariate analyses to identify risk factors for RFS are shown in Table 3. In univariate analysis, female sex (hazard ratio [HR]: 5.009, 95\% CI: $1.589-15.787, P=0.006$ ) and tumor size $\geq 3 \mathrm{~cm}$ (HR: 3.487, 95\% CI: $1.282-9.480, P=0.0141)$ were significantly related to shorter RFS. Multivariate analysis showed that female sex (HR: 7.360, 95\% CI: 1.64932.856, $P=0.009$ ), tumor size $\geq 3 \mathrm{~cm}$ (HR: $23.697,95 \%$ CI: 4.383-128.117, $P<0.001)$ and low $A R$ mRNA expression (HR: 0.202 , 95\% CI: $0.048-0.841, P=0.028$ ) were independent predictors of shorter RFS. 
Table 1 Patients' characteristics

\begin{tabular}{|c|c|}
\hline Age, median (range) & $74.1(40.5-88.8)$ \\
\hline \multicolumn{2}{|l|}{ Sex, n (\%) } \\
\hline Male & $48(90.6 \%)$ \\
\hline Female & $5(9.4 \%)$ \\
\hline \multicolumn{2}{|c|}{ Primary or recurrence, $\mathrm{n}(\%)$} \\
\hline Primary & $42(79.2 \%)$ \\
\hline Recurrence & $11(20.8 \%)$ \\
\hline \multicolumn{2}{|c|}{ Recurrence within one year, n (\%) } \\
\hline Yes & $9(17.0 \%)$ \\
\hline No & $44(83.0 \%)$ \\
\hline \multicolumn{2}{|l|}{ Tumor grade, n (\%) } \\
\hline Low & 39 (73.6\%) \\
\hline High & $14(26.4 \%)$ \\
\hline \multicolumn{2}{|l|}{ T stage, n (\%) } \\
\hline pTa & $42(79.2 \%)$ \\
\hline pT1 & $11(20.8 \%)$ \\
\hline \multicolumn{2}{|c|}{ Number of tumor, n (\%) } \\
\hline Single & $24(45.3 \%)$ \\
\hline Multiple & $29(54.7 \%)$ \\
\hline \multicolumn{2}{|l|}{ Tumor size, n (\%) } \\
\hline$<3 \mathrm{~cm}$ & $46(86.8 \%)$ \\
\hline$\geq 3 \mathrm{~cm}$ & $7(13.2 \%)$ \\
\hline \multicolumn{2}{|l|}{ Concurrent CIS, n (\%) } \\
\hline Yes & $2(3.8 \%)$ \\
\hline No & $51(96.2 \%)$ \\
\hline \multicolumn{2}{|c|}{ Immediate intravesical chemotherapy, n(\%) } \\
\hline Yes & $51(96.2 \%)$ \\
\hline No & $2(3.8 \%)$ \\
\hline \multicolumn{2}{|c|}{ Additional adjuvant intravesical chemotherapy, n (\%) } \\
\hline Yes & $12(22.6 \%)$ \\
\hline No & $41(77.4 \%)$ \\
\hline \multicolumn{2}{|l|}{ Second TUR, n (\%) } \\
\hline Yes & $6(11.5 \%)$ \\
\hline No & 47 (88.5\%) \\
\hline
\end{tabular}

CIS carcinoma in situ, TUR transurethral resection

\section{Discussion}

Although the function of AR signaling in $\mathrm{BC}$ is unclear, it is known to play important roles in prostate cancer occurrence and progression, and reportedly affects kidney, lung, breast and liver cancers [20].

$\mathrm{AR}$ is a nuclear steroid hormone receptor, composed of several domains, $\mathrm{N}$-terminal transactivation domain, DNA binding domain, a hinge region and a ligand-binding domain (LBD). In the cytoplasm, heat shock protein-90 (HSP90) binds with the LBD. As $5 \alpha$-dihydrotestosterone binds to AR, AR releases HSP90 and translocates into the nucleus, binds to the androgen-response element, and promotes gene transcription [3-6, 21].

AR signaling and the urinary tract may be critically associated. Studies in animal models have shown AR to be present in several tissues in lower urinary tract and may affect growth, differentiation and maintenance of urinary bladder tissue $[6,7,22,23]$.

Reportedly, AR signaling has a pivotal role in BC occurrence and progression. Testosterone increased the risk of N-butyl-N-(4-hydroxybutyl) nitrosamine (BBN)-induced bladder tumors in female rats, whereas diethylstilbestrol, a synthetic form of female hormone estrogen, inhibited incidence in male rats [8]. Also, intact female rats administered with testosterone had higher incidences of both bladder calculi and tumors, but oophorectomized rats did not, which implies that testosterone in combination with estrogen may contribute to $\mathrm{BC}$ formation [9]. Moreover, flutamide, a nonsteroidal antiandrogen therapy, inhibited BBN-induced bladder tumor incidence in rats, whereas finasteride, a $5 \alpha$-reductase inhibitor, did not; this suggests that testosterone itself has an effect in bladder carcinogenesis but its converting form, $5 \alpha$-dihydrotestosterone, does not [10].

Studies with animal models have indicated that AR has an important role in BC. Miyamoto et al. found that both male and female $A R$-knockout mice (ARKO) did not develop $B B N$-induced tumors, which suggests that AR has a crucial activity in bladder carcinogenesis [11]. That study also found that $25 \%$ of ARKO mice administered with dihydrotestosterone (DHT) developed tumors, compared with $50 \%$ of castrated male wild-type rats and $92 \%$ of intact wild-type male rats. These findings suggest that absence or low levels of androgen could restore AR signaling, or that androgens could induce bladder carcinogenesis independently of AR [7, 24]. Another study showed that mice lacking AR only in the urothelial tissues had lower incidence of BBN-induced $\mathrm{BC}$ and a higher survival rate than wild-type mice [12].

Therefore, the association between $\mathrm{BC}$ and $\mathrm{AR}$ has been the focus of several recent studies. Expression of AR have indicated to have high risk in bladder cancer occasion, but as for recurrence, expression of AR have shown to contribute to longer RFS. An immunohistochemical study of 169 patients indicated that recurrence was less likely for patients with $\mathrm{AR}^{+} \mathrm{BC}$ specimens [13]; another study showed that loss of AR was strongly associated with higher grade and more invasive tumors [14]. A study of the predictive value of $A R$ mRNA expression in $\mathrm{pT} 1$ NMIBC showed that high $A R$ mRNA expression was an independent predictor for longer RFS and cancer-specific survival [15], which was similar to our present findings that high $A R$ mRNA level was an independent predictor for RFS in NMIBC (including pTa and pT1).

Reportedly, AR pathway inhibitors have been shown to be effective in preventing $\mathrm{BC}$ recurrence. In patients 
Table 2 Spearman's rank-order correlation between each variables

\begin{tabular}{llllllllll}
\hline & Sex & Age & T stage & Tumor grade & Tumor size & Number of tumor & Recurrence/Primary & Instillation & AR mRNA expression \\
\hline Sex & 1.000 & 0.071 & -0.006 & 0.099 & -0.126 & 0.034 & 0.153 & -0.020 & -0.174 \\
Age & 0.071 & 1.000 & 0.056 & -0.160 & 0.063 & -0.093 & 0.056 & 0.010 & -0.009 \\
T stage & -0.006 & 0.056 & 1.000 & 0.432 & 0.075 & 0.372 & -0.262 & 0.057 & -0.110 \\
Tumor grade & 0.099 & -0.160 & 0.432 & 1.000 & 0.019 & 0.373 & -0.201 & 0.392 & -0.149 \\
Tumor size & -0.126 & 0.063 & 0.075 & 0.019 & 1.000 & -0.093 & -0.200 & -0.078 & 0.188 \\
Number of tumor & 0.034 & -0.093 & 0.372 & 0.373 & -0.093 & 1.000 & -0.095 & 0.492 & -0.051 \\
Recurrence/primary & 0.153 & 0.056 & -0.262 & -0.201 & 0.200 & -0.095 & 1.000 & 0.057 & -0.110 \\
Instillation & -0.020 & 0.010 & 0.057 & 0.392 & -0.078 & 0.492 & 0.057 & 1.000 & -0.085 \\
AR mRNA & -0.174 & -0.009 & -0.110 & -0.149 & 0.188 & -0.051 & -0.110 & -0.085 & 1.000 \\
expression & & & & & & & & & \\
\hline
\end{tabular}

mRNA messenger ribonucleic acid

with double primary cancers of the prostate and the bladder, androgen-deprivation therapy (ADT) to treat their prostate cancers reduced the risk of recurrence of $\mathrm{AR}^{+} \mathrm{BC}$ [16]. Enzalutamide, an AR-signaling inhibitor, is also reported to inhibit $\mathrm{AR}^{+} \mathrm{BC}$ cell growth in vivo [17]. BCG IVI has been the most effective therapy for NMIBC; its mechanism may be due to interaction between BCG and the AR pathway. DHT down-regulates NF-kB-mediated IL-6 expression, whereas AR blockers inhibit the effect of DHT. This result suggests that AR pathway inhibitors could improve the efficacy of BCG treatment [18].
As described above, previous clinical studies demonstrated that higher AR expression in both mRNA levels and protein levels were correlated with favorable outcome in NMIBC [13-15]. Moreover, our current study also demonstrated that higher AR mRNA expression levels were associated with longer recurrence-free survival in NMIBC. On the other hand, enhanced AR signaling pathway could play an important role in cancer initiation and progression in vitro and in vivo. There were discrepancies between our findings and previous reports from studies in vitro or in vivo $[8,10-12]$. Even

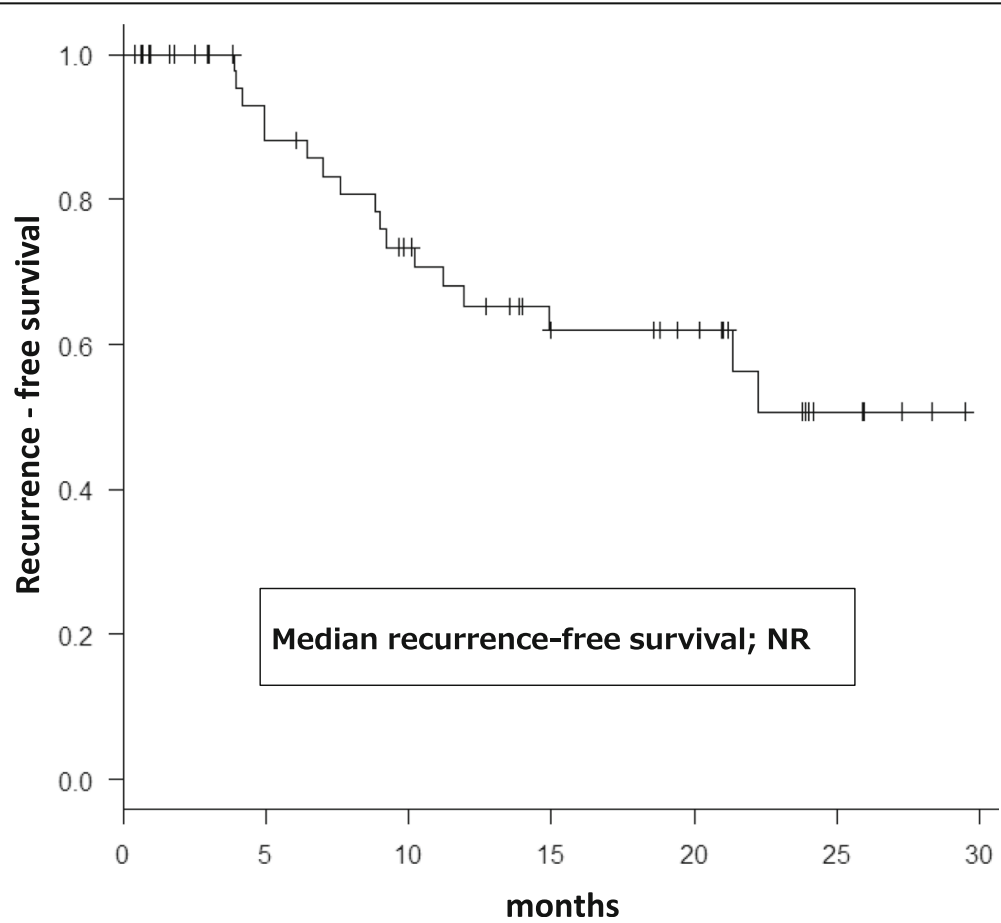

Fig. 1 Kaplan-Meier curve for RFS after TUR-BT. Within a median observation period of 10.2 months (range: 0.4-29.5 months), recurrence occurred in 17 patients (32.1\%) 


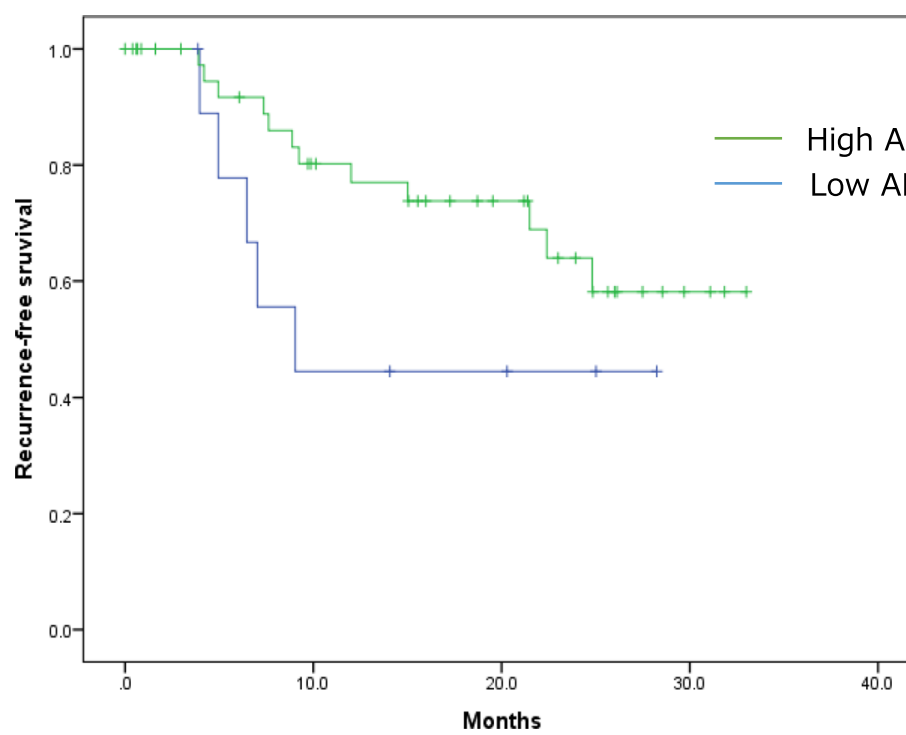

Fig. 2 Kaplan-Meier curve for recurrence-free survival (RFS), stratified by AR mRNA expression level. Green line: RFS curve for high AR mRNA expression level group; blue line: RFS for low $A R$ mRNA expression level group. The high AR mRNA-expressing group tended to have a longer median RFS (not reached) than did the low-AR group (9.04 months; $P=0.112$ )

though the reasons for discrepancies are unknown, several possible hypothesis have been suggested. It has to be considered that AR expression, and thus the role of AR, might change during the progression of bladder cancer, as indicated by the previously cited studies [14]. In addition, Sikic et al. reported that different AR subtype (AR 1 and AR2) has different role in bladder cancer carcionogenesis [14].

The mechanism of AR signaling in $\mathrm{BC}$ is still unclear, therefore, further studies of the AR pathway in NMIBC are needed.

Our study had several limitations. First, it was a retrospective study with relatively few patients and a short follow-up period. Second, CIS was not analyzed in this study. CIS is an essential risk factor of recurrence and progression in NMIBC, but our study cohort had only two BCs with coexisting CIS. Finally, for verify the role of AR pathway in NMIBC, not only AR mRNA expression levels, but also protein expression levels should be investigated in current study. Future clinical studies would need to estimate an appropriate sample size to include enough of these patients and investigate mRNA and protein expression levels simultaneously.

\section{Conclusions}

Our study show that $A R$ mRNA expression is an independent predictor for RFS in Japanese patients with NMIBC. The AR pathway is now attracting attention in $\mathrm{BC}$ research, and may provide new methods to treat bladder cancer and prevent its recurrence.

Table 3 Univariate and multivariate analyses for predicting recurrence-free survival

\begin{tabular}{|c|c|c|c|c|c|c|c|c|c|}
\hline \multirow[b]{3}{*}{ Sex } & \multirow[b]{3}{*}{ Women vs men } & \multicolumn{4}{|c|}{ Univariate } & \multicolumn{4}{|c|}{ Multivariate } \\
\hline & & \multirow{2}{*}{$\begin{array}{l}p \text { value } \\
0.006\end{array}$} & \multirow{2}{*}{$\begin{array}{l}\text { HR } \\
5.009\end{array}$} & \multicolumn{2}{|c|}{ HR 95\% Cl } & \multirow{2}{*}{$\begin{array}{l}p \text { value } \\
0.009\end{array}$} & \multirow{2}{*}{$\frac{H R}{7.360}$} & \multicolumn{2}{|c|}{ HR95\% Cl } \\
\hline & & & & 1.589 & 15.787 & & & 1.649 & 32.856 \\
\hline Age & High vs low & 0.324 & 1.633 & 0.617 & 4.325 & 0.453 & 0.640 & 0.199 & 2.054 \\
\hline T stage & pT1 vs pTa & 0.925 & 1.056 & 0.342 & 3.261 & 0.096 & 5.274 & 0.743 & 37.435 \\
\hline Tumor grade & High vs low & 0.526 & 0.694 & 0.225 & 2.142 & 0.657 & 0.650 & 0.097 & 4.357 \\
\hline Tumor size & $\geq 3 \mathrm{~cm}$ vs $<3 \mathrm{~cm}$ & 0.014 & 3.487 & 1.282 & 9.480 & $<0.001$ & 23.697 & 4.383 & 128.117 \\
\hline Number of tumor & Multiple vs single & 0.189 & 0.527 & 0.203 & 1.370 & 0.477 & 1.688 & 0.398 & 7.148 \\
\hline Tumor recurrence & Recurrence vs primary & 0.531 & 1.397 & 0.491 & 3.973 & 0.052 & 4.122 & 0.988 & 17.190 \\
\hline Instillation & Yes vs no & 0.068 & 0.253 & 0.058 & 1.108 & 0.088 & 0.182 & 0.026 & 1.290 \\
\hline AR mRNA expression & High vs low & 0.123 & 0.438 & 0.153 & 1.250 & 0.028 & 0.202 & 0.048 & 0.841 \\
\hline
\end{tabular}

mRNA messenger ribonucleic acid, $\mathrm{HR}$ hazard ratio, $\mathrm{Cl}$ confidence interval 


\section{Abbreviations}

AR: Androgen receptor; ARKO: AR-knockout (mice); BBN: N-butyl-N-(4hydroxybutyl) nitrosamine; BC: Bladder cancer; BCG: Bacillus Calmette-Guérin; CIS: Carcinoma in situ; DHT: Dihydrotestosterone;" HR: Hazard ratio; HSP90: Heat shock protein-90; IVI: Intravesical instillation; LBD: Ligand-binding domain; MIBC: Muscular invasive bladder cancer; NMIBC: Non-muscular invasive bladder cancer; RFS: Recurrence-free survival; RT-qPCR: Real-time quantitative polymerase chain reaction; TUR-BT: Transurethral resection of bladder tumor; XIST: X-inactive specific transcript

\section{Acknowledgements}

We thank Marla Brunker, from Edanz Group (www.edanzediting.com/ac) for editing a draft of this manuscript.

\section{Funding}

None.

\section{Availability of data and materials}

Due to ethical restrictions, the raw data underlying this paper are available upon request to the corresponding author.

\section{Authors' contributions}

Conceived and designed the experiments: MY, TK, KI, MY, HI, HU, YM Analyzed data: MY, TK, KI, YM. Performed the experiments: MY, TK, YI, HI. Wrote the paper: MY, TK, KI, MY, HU, YM. All authors read and approved the final manuscript.

\section{Ethics approval and consent to participate}

IRB approval for Yokohama City University. Informed consent was obtained in the form of opt-out on the web-site. Those who rejected were excluded.

\section{Consent for publication}

Not applicable.

\section{Competing interests}

The authors declare that they have no competing interests.

\section{Publisher's Note}

Springer Nature remains neutral with regard to jurisdictional claims in published maps and institutional affiliations.

\section{Author details}

'Department of Urology and Renal Transplantation, Yokohama City University Medical Center, 4-57 Urafune-cho, Minami-ku, Yokohama 232-0024, Japan. ${ }^{2}$ Department of Urology, Yokohama City University Graduate School of Medicine, Yokohama, Japan. ${ }^{3}$ Photocatalyst Group, Special Research Laboratory, Kanagawa Academy of Science and Technology, Kawasaki, Japan.

Received: 24 November 2017 Accepted: 25 March 2019

Published online: 08 April 2019

\section{References}

1. Torre LA BF, Siegel RL, Ferlay J, Lortet-Tieulent J, Jemal A. Global cancer statistics, 2012. CA Cancer J Clin. 2015:65:87-108.

2. MT HM, Shibata A, Katanoda K, Sobue T, Nishimoto H. Japan Cancer surveillance research group. Cancer incidence and incidence rates in Japan in 2009: a study of 32 population-based cancer registries for the monitoring of Cancer incidence in Japan (MCIJ) project. Jpn J Clin Oncol. 2015:45:884-91.

3. Li PCJ, Miyamoto H. Androgen receptor signaling in bladder Cancer. Cancers (Basel). 2017;9. https://doi.org/10.3390/cancers9020020.

4. Li YIK, Miyamoto $\mathrm{H}$. The role of the androgen receptor in the development and progression of bladder cancer. Jpn J Clin Oncol. 2012;42:569-77.

5. McBeth L GM, Selman S, Hinds TD Jr. Involvement of the androgen and glucocorticoid receptors in bladder Cancer. Int J Endocrinol 2015. https:// doi.org/10.1155/2015/384860

6. Rahmani AHAM, Babiker AY, Khan AA, Aly SM, Rizvi MA. Implication of androgen receptor in urinary bladder cancer: a critical mini review. Int J Mol Epidemiol Genet. 2013;12(4):150-5.

7. Lombard APMM. The emerging role of the androgen receptor in bladder cancer. Endocr Relat Cancer. 2015;22:R265-77.
8. Okajima EHT, Iriya K, ljuin M, Matsushima S. Effects of sex hormones on development of urinary bladder tumours in rats induced by N-butyl-N-(4hydroxybutyl) nitrosamine. Urol Res. 1975;3:73-9.

9. Terada SSN, Uchide K, Akasofu K, Nishida E. Effect of testosterone on the development of bladder tumors and calculi in female rats. Gynecol Obstet Investig. 1992;34:105-10.

10. Imada SAH, Ami Y, Koiso K, Ideyama Y, Takenaka T. Promoting effects and mechanisms of action of androgen in bladder carcinogenesis in male rats. Eur Urol. 1997:31:360-4.

11. Miyamoto $H Y Z$, Chen $Y T$, Ishiguro $H$, Uemura $H$, Kubota $Y$, Nagashima $Y$, Chang YJ, Hu YC, Tsai MY, Yeh S, Messing EM, Chang C. Promotion of bladder cancer development and progression by androgen receptor signals. J Natl Cancer Inst. 2007;4(99):558-68.

12. Hsu JWHI, Xu D, Miyamoto H, Liang L, Wu XR, Shyr CR, Chang C. Decreased tumorigenesis and mortality from bladder Cancer in mice lacking urothelial androgen receptor. Am J Pathol. 2013;182:1811-20.

13. Nam JKPS, Lee SD, Chung MK. Prognostic value of sex-hormone receptor expression in non-muscle-invasive bladder cancer. Yonsei Med J. 2014;55: 1214-21.

14. Miyamoto HYJ, Chaux A, Zheng Y, Hsu I, Izumi K, Chang C, Messing EM, Netto GJ, Yeh S. Expression of androgen and oestrogen receptors and its prognostic significance in urothelial neoplasm of the urinary bladder. BJU Int. 2012;109:1716-26.

15. Sikic DBJ, Hartmann A, Burger M, Erben P, Denzinger S, Eckstein M, Stöhr R, Wach S, Wullich B, Keck B, Wirtz RM, Otto W. High androgen receptor mRNA expression is independently associated with prolonged Cancerspecific and recurrence-free survival in stage T1 bladder Cancer. Transl Oncol. 2017;10:340-5.

16. Izumi KTM, Miyamoto H, Hara Y, Kishida T, Chiba K, Murai T, Hirai K, Suzuki K, Fujinami K, Ueki T, Udagawa K, Kitami K, Moriyama M, Miyoshi Y, Tsuchiya F, Ikeda I, Kobayashi K, Sato M, Morita S, Noguchi K, Uemura H. Androgen deprivation therapy prevents bladder cancer recurrence. Oncotarget. 2014;5: 12665-74.

17. Kawahara TIH, Kashiwagi E, El-Shishtawy KA, Li Y, Reis LO, Zheng Y, Miyamoto H. Enzalutamide inhibits androgen receptor-positive bladder cancer cell growth. Urol Oncol. 2016;34:432.e15-23.

18. Chen FLP, Zhang G, Iwamoto Y, See W. Androgen dependent regulation of bacillus Calmette-Guerin induced interleukin-6 expression in human transitional carcinoma cell lines. J Urol. 2003;170:2009-13.

19. Budczies J KF, Sinn BV, Győrffy B, Schmitt WD, Darb-Esfahani S, Denkert C. Cutoff finder: a comprehensive and straightforward web application enabling rapid biomarker cutoff optimization. PLoS One. 2012;7:e51862.

20. Chang CLS, Yeh S, Chang TM. Androgen receptor (AR) differential roles in hormone-related tumors including prostate, bladder, kidney, lung, breast and liver. Oncogene. 2014;19:3225-34.

21. Davey RAGM. Androgen receptor structure, function and biology: from bench to bedside. Clin Biochem Rev. 2016;37:3-15.

22. Salmi SSR, Gustafsson JA, Mäkelä S. Co-localization of androgen receptor with estrogen receptor beta in the lower urinary tract of the male rat. J Urol. 2001:166:674-7.

23. Shortliffe LMYY, Behr B, Wang B. Testosterone changes bladder and kidney structure in juvenile male rats. J Urol. 2014;191:1913-9.

24. Inoue SMT, Miyamoto H. Role of the androgen receptor in urothelial cancer. Mol Cell Endocrinol. 2017.

Ready to submit your research? Choose BMC and benefit from:

- fast, convenient online submission

- thorough peer review by experienced researchers in your field

- rapid publication on acceptance

- support for research data, including large and complex data types

- gold Open Access which fosters wider collaboration and increased citations

- maximum visibility for your research: over $100 \mathrm{M}$ website views per year

At $\mathrm{BMC}$, research is always in progress.

Learn more biomedcentral.com/submission 